\title{
A review: Conversion of bioglycerol into 1,3-propanediol via biological and chemical method
}

\author{
C.S. Lee ${ }^{a}$, M.K. Aroua ${ }^{\text {a,*, W.M.A.W. Daud }}{ }^{\text {a }}$, P. Cognet $^{\text {b }}$, Y. Pérès-Lucchese ${ }^{\text {b }}$, \\ P-L Fabre ${ }^{\mathrm{c}}$, O. Reynes ${ }^{\mathrm{c}}$, L. Latapie ${ }^{\mathrm{c}}$ \\ a Department of Chemical Engineering, Faculty of Engineering, University of Malaya, 50603 Kuala Lumpur, Malaysia \\ ${ }^{\mathrm{b}}$ Laboratory of Chemical Engineering (Labége), BP 84234 Campus INP-ENSIACET, 4 allée Emile Monso, 31432 Toulouse Cedex 4, France \\ ${ }^{\mathrm{C}}$ Laboratory of Chemical Engineering (Rangueil), University Paul Sabatier, 118 route de Narbonne, 31062 Toulouse Cedex 9, France
}

\section{A R T I C L E I N F O}

Article history:

Received 15 January 2014

Received in revised form

24 August 2014

Accepted 5 October 2014

Available online 14 November 2014

Keywords:

1,3-Propanediol

Biocatalysis

Catalysis

Biodiese
A B S T R A C T

Today, the price of glycerol has dramatically dropped due to its oversupply from biodiesel production as well as oleochemical industry. Thus, it is essential to develop processes to transform bioglycerol into commercially valued products which is important to ensure sustainability in the biodiesel and oleochemical industries. One possibility is to transform it in propanediols, which have numerous applications such as food additives, raw material in pharmaceutical and cosmetic industries. In this paper, methods of conversion of glycerol into 1,3-propanediol are reviewed and discussed in detail.

c 2014 Elsevier Ltd. All rights reserved.

\section{Contents}

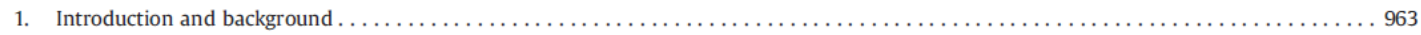

1.1. Biodiesel. .

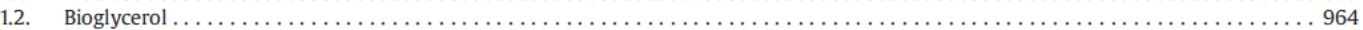

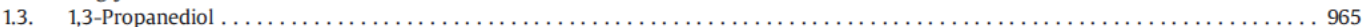

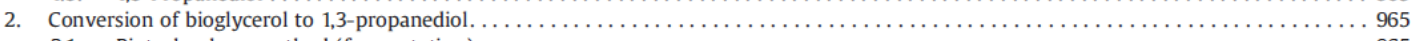

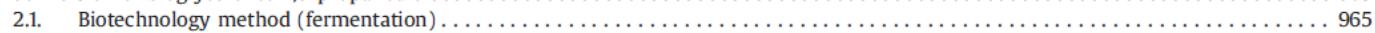

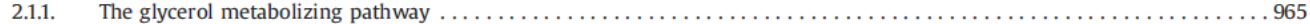

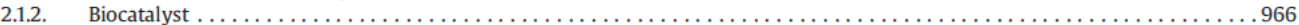

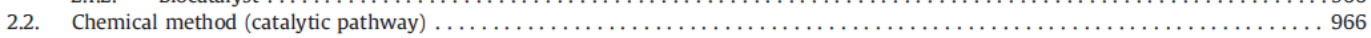

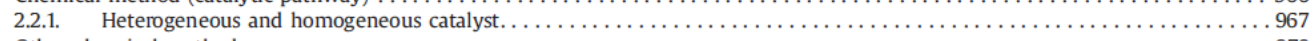

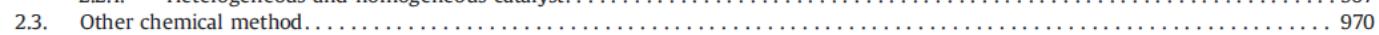

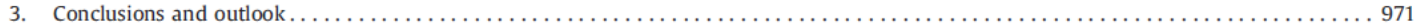

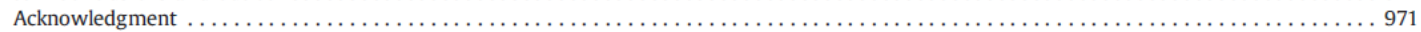

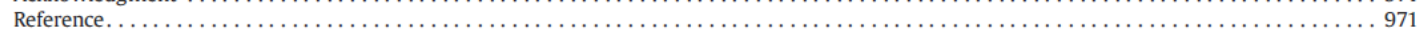

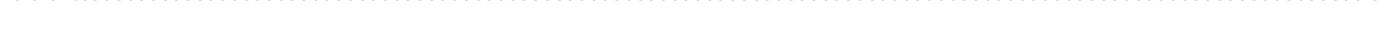

\section{Introduction and background}

\subsection{Biodiesel}

*Corresponding author. Tel.: +60 3 79674615; fax: +60379675319. E-mail address: mk_aroua@um.edu.my (M.K. Aroua).

http://dx.doi.org/10.1016/j.rser.2014.10.033

1364-0321/o 2014 Elsevier Ltd. All rights reserved.
The decrease of the world oil supplies and the unsteadiness of world oil market caused the increase of the price for both fossil fuel and its derivatives. Despite that, it is necessary to make great 
efforts to reduce $\mathrm{CO}_{2}$ emissions from the fossil fuel combustion as this greenhouse gas is the fundamental source of global warming. For these ecological and economic reasons that much interest has been taken in converting biomass resources into biofuels. One of biofuels that used worldwide is biodiesel $[1,2]$.

In United States and Europe, biodiesel is a fast growing product as their government policies seek to spur the development of renewable transportation fuels. In year 2010, Europe has produced 10 million mt of biodiesel but since 2011, the biodiesel production in Europe has been decreased and subsequently increased the import of biodiesel from other countries such as US, Asia, Brazi and Argentina. This move has urged the biodiesel production from these countries grew exponentially up to 10 million $\mathrm{mt}$ in year 2011 [3].

Biodiesel is produced by transesterification or alcoholysis process of biological feedstock e.g. edible vegetable oils that are rich in triacylglycerol (TAG) with alcohols such as methanol. Biodiesel consist of the mixture of alkyl esters of fatty acids and aliphatic alcohols. During the engines combustion, biodiesel is either employed alone or mixed with the conventional diesel fuel. It has lower exhaust emission of dust, hydrocarbon, carbon dioxide or carbon monoxide and smoke. On top of that, biodiesel is less toxic and more biodegradable comparing to fossil diesel which causes it to be an environmentally friendly fuel $[4,5]$.

When vegetable oil goes through the transesterification process to become biodiesel (or fatty acid methyl ester), glycerol is a byproduct of the chemical reaction. In the transesterification process, $3 \mathrm{~mol}$ of fatty acid methyl esters (FAME) and $1 \mathrm{~mol}$ of glycerol are synthesized as shown in Scheme 1.1. The glycerol by-product yields approximately $10 \mathrm{wt} \%$ of the total product. Today, twothird of the world glycerol supply is produced from biodiesel $[3,6]$.

\subsection{Bioglycerol}

Glycerol is a colorless and odorless organic liquid; it is named also as glycerin, which is widely used in the production of cosmetic products, pharmaceuticals, foods and etc. [7].

Bioglycerol is the by-product which is formerly obtained largely from soap manufacturing process, microbial fermentation, hydrogenolysis of glucose in the mixture of polyols, fatty ester and fatty acid production. In recent years, the bioglycerol is commonly generated through the transesterification of rapeseed, soybean, sunflower or palm oils during the manufacturing of biodiesel for modern fuels and fuels components (Scheme 1.1) [8,9].

Basically, glycerol from biodiesel industry can be classified into two categories based on their purity, i.e. crude glycerol (with $60-80 \%$ purity) and pure/ refined glycerol (with $99.1-99.8 \%$ purity) as shown in Table 1.1 [10]. The crude glycerol obtained from the biodiesel production has heavy contamination of methanol (14-50\%) and it is unsuitable to use in pharmaceutical industry. Generally, only purified or refined glycerols with purity above $99 \%$ are commercial valuable, their grades and usages are summarized in Table 1.2 [11]. Thus, high cost is paid to remove methanol make the production of ultrapure glycerol non-viable economically for small and medium production plants $[12,13]$. The marketing price of pure glycerol is greatly relied on the cost from refinery process such as distillation, chemical treatment, extraction, ion-exchange, decantion, adsorption and crystallization [14]. In the past few years, the global price of pure glycerol varied from $\$ 1.10 / \mathrm{kg}$ to

Table 11

Chemicals content in crude glycerol and purified glycerol [10].

\begin{tabular}{lll}
\hline Parameter & Crude glycerol & Purified glycerol \\
\hline Glycerol content (\%) & $60-80$ & $99.1-99.8$ \\
Moisture contents (\%) & $1.5-6.5$ & $0.11-0.8$ \\
Ash (\%) & $1.5-2.5$ & 0.054 \\
Soap (\%) & $3.0-5.0$ & 0.56 \\
Acidity (pH) & $0.7-1.3$ & $0.10-0.16$ \\
Chloride (ppm) & ND & 1.0 \\
Colour (APHA) & Dark & $34-45$ \\
\hline
\end{tabular}

Table 1.2

Grades and usages of commercial purified glycerol [11].

\begin{tabular}{|c|c|c|}
\hline Grade & Type of glycerol & Usage \\
\hline Grade-I & $\begin{array}{l}\text { Technical grade } \\
\sim 99.5 \%\end{array}$ & $\begin{array}{l}\text { Intermediate compound for various } \\
\text { chemicals however not applied to food or } \\
\text { drug formulation }\end{array}$ \\
\hline Grade-II & *USP grade $96-99.5 \%$ & $\begin{array}{l}\text { Food products, pharmaceuticals and } \\
\text { cosmetics }\end{array}$ \\
\hline Grade-III & $\begin{array}{l}\text { Kosher or USP } / * F C C \\
\text { grade } 99.5-99.7 \%\end{array}$ & Kosher foods and drinks \\
\hline
\end{tabular}

* USP-United States pharmacopeia.

* FCC-Food chemical codex.

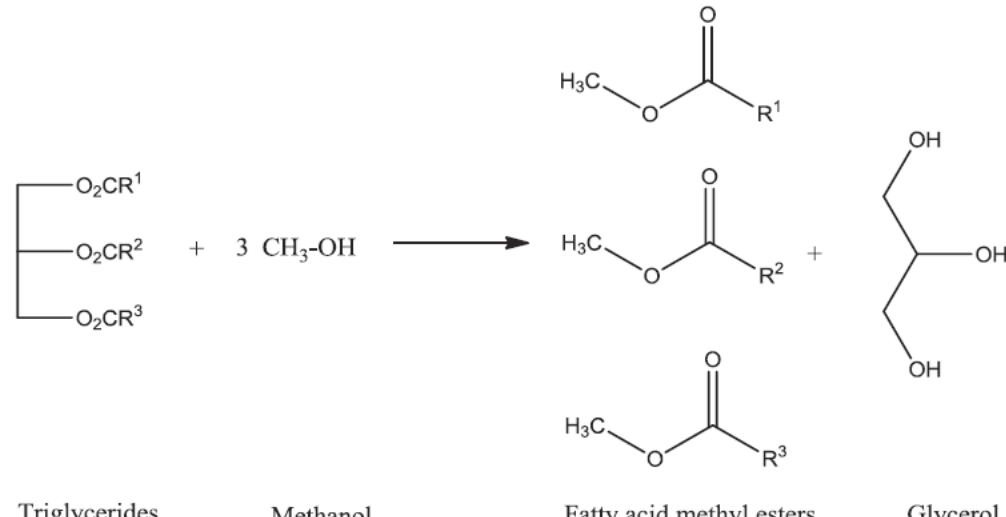

Scheme 1.1. Transesterfication of triglycerides with methanol. 
$\$ 3.30 / \mathrm{kg}$ which was very much higher as compared to the crude glycerol price from $\$ 0.04 / \mathrm{kg}$ to $\$ 0.33 / \mathrm{kg}$ [13].

On top of that, as reported by Wang and his co-workers, the world biodiesel production has significantly increased with an average growth of $42 \%$ annually and expected to reach 37 billion gallons by 2016 [15]. With the rapid rise of biodiesel production in the world, crude glycerol as one of the by-product from the process has dramatically increased and become worthless. Based on a report in United States in year 2007, the price of pure glycerol decreased exponentially from $\$ 1.50 / \mathrm{kg}$ (before the rapid growth of biodiesel production) to $\$ 0.66 / \mathrm{kg}$ and the price of crude glycerol dropped from $\$ 0.55 / \mathrm{kg}$ to $\$ 0.11 / \mathrm{kg}$ [16]. Therefore, the manufacturers are forced to invest large amount of money to remove the unwanted glycerol away from their plants $[17,18]$.

Thus, it is essential to find alternative uses for glycerol. It was reported that many high-value chemicals could be produced by using glycerol as raw material, such as citric acid, lactic acid, DHA, DCP, hydrogen, ethanol, etc. [19-23]. One possibility is to transform it in propanediols. Indeed, the 1,3-propanediol have numerous applications such as fragrances, perfumes, paints, coatings, adhesives, laminates, lab-scale chemicals and personal care products.

\subsection{1,3-Propanediol}

The world production of 1,3-propanediol is growing rapidly and achieving 100 million pounds annually [24]. The speedy growth of global 1,3-propandiol market is highly related to the increasing market demand of its derivatives into highly valuable products. In year 2012, the global demand for 1,3-propanediol was $60.2 \mathrm{kt}$ and is expected to reach approximately $150 \mathrm{kt}$ by year 2019 [25]. Based on another marketing research report, the price of 1,3propanediol is estimated to grow from \$157 million in 2012 to $\$ 560$ million in 2019 [26].

1,3-Propanediol which is commonly named by its abbreviation $\mathrm{PDO}$, is an important chemical intermediate in manufacturing of polyethers, polyurethanes and polyesters. It is also widely used in food, cosmetic and pharmaceutical industries. Besides, PDO may also be used as intermediate to synthesize biocides and heterocyclic compounds [27-30].

Currently, PDO is widely used in the manufacture of polytrimethylene terephthalate (PTT) as fiber for carpets (Fig. 1.1) [27,31,32]. PDO is suitable for producing PTT because it does not impart the stiffness of ethylene glycol and avoids also the floppiness of 1,4-butanediol and 1,6-hexandiol [33]. The PTT that derived from PDO is a coil-like or zig-zag shape which has better characteristic in stretching and stretch-recovering. In addition, the PDO-based polyester has also lower dyeing temperature, higher UV resistance and better wash-fastness than other commercially available polyesters [24]. The common trademarks of PTT found in the market are CDP Natureworks (from Dow Chemical), Dupont's Soronam (from Dupont) and Shell Chemical's CorterraTM (from Shell) [34].

At present, the conventional processes of synthesis of the 1,3-propanediol are through hydration of acrolein, hydroformylation of ethylene oxide and more recently through enzymatic transformation of glycerol [23]. Many processes have been developed to produce PDO from crude and pure glycerol. According to

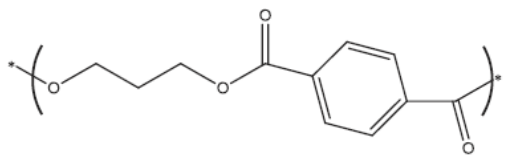

Fig. 1.1. Polytrimethylene terephthalate (PTT).
Zeng and Wang, PDO could be produced from glycerol through biological fermentation pathway using microorganisms such as Citrobacter freudii, Klebsiella pheumonia, or Clostridium butyricum $[33,35,36]$. PDO could also be produced in catalytic chemical reaction by selective deoxygenation or via hydrogenolysis of glycerol [24]. In the following sections, conversion methods for glycerol to PDO will be discussed in more details.

\section{Conversion of bioglycerol to 1,3-propanediol}

\subsection{Biotechnology method (fermentation)}

The biological conversion of glycerol into PDO is mainly attained by the anaerobic bacteria fermentation process or micro-aerobic fermentation $[32,37,38]$. The bacterial fermentation of glycerol to PDO has been known for more than 130 years. PDO was first observed as a fermentation product in 1881 by Freund [35]. Today, the common PDO fermenting bacteria that has been widely investigated so far belong to Clostridium, Enterobacter and Lactobacillus [39].

\subsubsection{The glycerol metabolizing pathway}

When glycerol has entered the bacteria cell, it can be metabolized by a dismutation process involving two parallel pathways under anaerobic condition. The bioprocess is carried out at physiological temperature $\left(37^{\circ} \mathrm{C}\right)$ and atmospheric pressure [40]. In the first pathway, glycerol is oxidized via dihydroxyacetone (DHA) to pyruvate (glycolysis). Dihydroxyacetone is first generated from glycerol through dehydrogenation process with an NAD -linked enzyme [40,41], followed by the phosphorylation process by an ATP-dependent kinase to form pyruvate. In the other pathway, glycerol is reduced via 3-hydroxypropionaldehyde (3-HPA) to PDO. 3-HPA is formed by dehydration of glycerol with a B12-dependent enzyme. Then, 3-HPA is reduced to PDO by an NADH-oxidoreductase, thus regenerating $\mathrm{NAD}^{+}[42,43]$. The biochemical pathways of glycerol fermentation are shown in Scheme 2.1 [44].

During the fermentation process, pyruvate obtained from the glycolysis pathway will compete with 3-HPA for NADHoxidoreductase to form other by-products such as ethanol, citric acid, acetic acid, butanol and etc. The by-products compositions may differ based on the microorganisms involved in the process and also the process conditions. For example, the PDO formation is favorable to perform at $\mathrm{pH} 6.5-7.5$ as $\mathrm{pH}$ lower than 6.5 will stimulates the formation of 2,3-butanediol $[40,41,45]$. The formation of various pyruvate-derived by-products may result in a decrease of PDO yield. According to the results obtained by Kivistö and his co-workers, by-product acetate that formed in the fermentation process had an inhibitory effect on the growth of PDO [46]. In an ideal anaerobic fermentation process, the maximum theoretical yield calculated for PDO conversion from glycerol is $0.875 \mathrm{~mol} / \mathrm{mol}$ glycerol. During this process, all acetyl-co-A is believed to be consumed by the citric acid cycle with no feeding of $\mathrm{NADH}$ to the oxidative phosphorylation pathway to form of acetate, thus leads a high efficacy in creating the reducing equivalents [47].

In order to obtain the optimum yield of PDO, the by-products formed in the pyruvate reduction pathway should be maintained at the lowest level or stopped them from being formed. Initially, researcher has to determine the main competitors during the production of PDO and remove them away from the process. For example, Zhang et al. [48] found out that ethanol is the major byproduct in the production of PDO by using Klebsiella pneumoniae YMU2 as biocatalyst. Two NADH molecules are consumed to form of one ethanol molecule. In this case, acetaldehyde dehydrogenase (ALDH) will oxidize one NADH molecule in order to convert the 


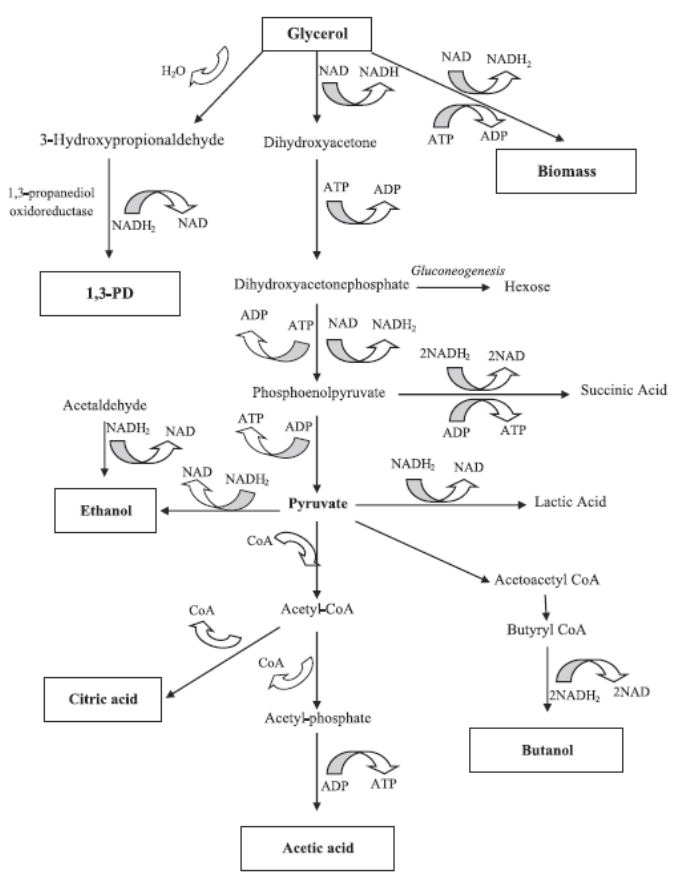

Scheme 2.1. Glycerol metabolism for the production of value-added products.

acetyl Co-A into acetaldehyde, thereafter formation of ethanol by ethanol dehydrogenase and further oxidize another NADH molecule. Therefore these enzymes (acetaldehyde dehydrogenase and ethanol dehydrogenase) which oxidize NADH to produce ethanol are the main competitors during the production of PDO. The authors tried to inactivate the gene coding for ALDH and success fully improved the yield up to $0.7 \mathrm{~mol} / \mathrm{mol}$ [48]. Another study was reported by $\mathrm{Xu}$ et al. [49], by colliding out the IdhA gene in K. pneumonia HR526 to stop the behavior of lactate dehydrogenase. Lactate was stopped being produced and the highest PDO yield obtained is $0.52 \mathrm{~mol} / \mathrm{mol}$ [49].

As mentioned earlier, biocatalysts widely used in fermentation of glycerol can be divided into two major groups, which are Clostridiaceae and Enterobacteriaceae; others minor groups are such as Lactobacilli, Thermophilic microorganisms and some other miscellaneous microorganisms. More precisely, the species included K. pneumonia, C. butyricum, Citrobacter freundii, Lactobacillus reuteri, Halonaerobium saccharolyticum and etc. [31,46,50-52].

\subsubsection{Biocatalyst}

Numerous studies have been carried out on Clostradia in the production of PDO from glycerol [53]. The famous producers within this group are Clostridium butyricium, C. acetpbutyricum, C. Pasteurianum, C. beijerinc kii and C. diolis [53-57]. According to Metsoviti et al., Clostridium sp. can breakdown glycerol only under anaerobic conditions [58]. In their studied, the performances of 84 types of bacterial strains were screened by using glycerol as carbon source. Twelve of them were identified capable of consuming raw glycerol under anaerobic conditions, while five strains consumed glycerol under aerobiosis. Based on the results obtained by Metsoviti et al. C. butyricum could produce PDO in quantities up to $11.3 \mathrm{~g} / \mathrm{L}$ [58].
Wilkens and his co-workers had optimized the biotechnological process for the production of PDO from pure glycerol and crude glycerol obtained in biodiesel production. Based on their study, C. butyricum AKR102a was used in fed-batch glycerol fermentation. The highest PDO yield attained from pure glycerol is $93.7 \mathrm{~g} / \mathrm{L}$, while for crude glycerol the PDO yield reached $76.2 \mathrm{~g} / \mathrm{L}$ [51]. Fermentation of glycerol by $C$. pasteurianum was described by Jensen et al. A batch fermentation reactor with in situ removal of butanol was designed by using gas stripping. Higher productivities of 1,3-propanediol in both technical (211 mmol) and crude glycerol $(169 \mathrm{mmol})$ were achieved when butanol was removed [59]. Myszka et al. had done a study on C. bifermentans, the final PDO concentration obtained reach $16.98 \mathrm{~g} / \mathrm{L}$ other products obtained are ethanol, lactic, formic, and acetic acid [60].

Among the Enterobacteriaceae, Klebsiella pheumonieae [31] and C. freundii [61] are the most common species used to convert glycerol into PDO. Recently, Jalasutram and his co-workers carried out a study on the fermentation conversion of raw glycerol into PDO by using Klebsiella pheumoniae 141B strain. The optimum yield of PDO achieved from this study was $24.82 \mathrm{~g} / \mathrm{L}$ [62].

Five different grades of crude glycerol (obtained from biodiesel preparation using jatropha, soybean, sunflower, rice bran and linseed oils) were converted to PDO by Anand et al. using C. freundii as the biocatalyst. The highest PDO yields attained from this batch fermentation are about 22-25 g/L [50]. Another research on conversion of glycerol to PDO by $C$. freundii was carried out by Metsoviti et al. The PDO produced under this anaerobic batch fermentation is about $10.1 \mathrm{~g} / \mathrm{L}$ [58].

Besides the PDO-forming microorganism stated above, Lactobacillacae is another common microorganism used to form PDO from glycerol. Lactobacillus brevis and L. Bushneri are well examined strains; they can produce PDO from glycerol during the fermentation process of glucose to acetic acid or ethanol and lactic acid [63-65]. L. reuteri is a recognized probiotic that offers an alternative for production of 1,3-propanediol in glucose/glycerol co-fermentations. Baeza-Jimenez et al. studied the effect of glucose on PDO production under anaerobic conditions by $L$. reuteri ATCC 23272. The most optimum glucose/glycerol ratio achieved is 0.5 which allowed the highest PDO production (16.81 g/L) [52].

Wittlich et al. reported that thermophilic fermentation is more cost effective than other fermentation processes. During thermophilic fermentation, hot effluents from previous processing steps are directly used and the cooling facilities for fermenters are unnecessary. Thus, the energy and cost that used to heat up the fermentation fluid during the distillation process at downstream processing would be reduced. The author and his co-workers had screened 60 different strains, 16 of them found to be able to convert glycerol to 1,3-PDO. The best strain, AT1, produced $6.4 \mathrm{~g} / \mathrm{L}$ of 1,3-PDO [66]. Seyfried et al. reported that Caloramator viterbensis with an optimum temperature at $60{ }^{\circ} \mathrm{C}$ could produce PDO from glycerol at yield of $0.69 \mathrm{~mol} / \mathrm{mol}$ [67]. Besides the above mentioned groups of PDO-forming species, Anaerobacvibrio burkinabensis [68], Iliobacter polytropus [69] and Pelobacter venetianus [70] may also be able to form PDO from glycerol but only in small quantities.

Recently, a halophilic fermentation bacterium, $H$. saccharolyticum subsp. Saccharolyticum was observed to produce PDO from glycerol [71]. In the research that was done by Kivistö and his co-workers in, the highest PDO yields $(0.61-0.63 \mathrm{~mol} / \mathrm{mol}$ glycerol) were obtained at vitamin B12 concentrations $64-480 \mu \mathrm{g} / \mathrm{L}$ with $H$. saccharolyticum as the producer in the glycerol fermentation process [46]. Table 2.1 shows the summary of fermentation results of PDO production from glycerol.

\subsection{Chemical method (catalytic pathway)}

Currently, PDO is produced chemically through the derivatives from petroleum acrolein (Degussa-DuPont routes) or ethylene oxide 
Table 21

Fermentation results of PDO production from glycerol.

\begin{tabular}{|c|c|c|c|c|c|c|}
\hline Substrate & Type of species & Type of families & By-product & Process & $\begin{array}{l}\text { Product } \\
\text { (concentration/yield) }\end{array}$ & Ref. \\
\hline Glycerol & $\begin{array}{l}\text { Halanaerobium saccharolyticum } \\
(\text { Strain: D6643 }\end{array}$ & Halanaerobiaceae & Acetate & Batch & $0.61-0.63 \mathrm{~mol} / \mathrm{mol}$ & [46] \\
\hline Crude glycerol & Clostridium butyricum (AKR102a) & Clostridiaceae & Acetic acid butyric acid & Fed-batch & $76.2 \mathrm{~g} / \mathrm{L}$ & [51] \\
\hline Glycerol & $\begin{array}{l}\text { Clostridium butyricum } \\
\text { (NRRLB-23495) }\end{array}$ & Clostridiaceae & $\begin{array}{l}\text { Acetic acid lactic acid } \\
\text { butyric acid }\end{array}$ & Batch & $11.3 \mathrm{~g} / \mathrm{L}$ & [58] \\
\hline Glycerol & $\begin{array}{l}\text { Citrobacter freundii } \\
\text { (FMCC-B294 } \\
\text { (VK-19)) }\end{array}$ & Enterobacteriaceae & $\begin{array}{l}\text { Acetic acid lactic acid } \\
\text { formic acid }\end{array}$ & Batch & $10.1 \mathrm{~g} / \mathrm{L}$ & [58] \\
\hline Glycerol & Klebsiella oxytoca (FMCC-197) & Enterobacteriaceae & Ethanol 2,3-butanediol & Batch & $3.8 \mathrm{~g} / \mathrm{L}$ & [58] \\
\hline Glycerol & Citrobacter freundii & Enterobacteriaceae & Lactic acid acetic acid & Batch & $25.36 \mathrm{~g} / \mathrm{L}$ & {$[30,50]$} \\
\hline $\begin{array}{l}\text { Crude glycerol } \\
\text { (jatropha based) }\end{array}$ & Citrobacter freundii & Enterobacteriaceae & Lactic acid acetic acid & Batch & $23.40 \mathrm{~g} / \mathrm{L}$ & {$[30,50]$} \\
\hline $\begin{array}{l}\text { Crude glycerol } \\
\text { (soybean based) }\end{array}$ & Citrobacter freundii & Enterobacteriaceae & Lactic acid acetic acid & Batch & $21.42 \mathrm{~g} / \mathrm{L}$ & {$[30,50]$} \\
\hline $\begin{array}{l}\text { Crude glycerol } \\
\text { (sunflower based) }\end{array}$ & Citrobacter freundii & Enterobacteriaceae & Lactic acid acetic acid & Batch & $25.63 \mathrm{~g} / \mathrm{L}$ & {$[30,50]$} \\
\hline Crude glycerol & Klebsiella pneumonia (141B) & Enterobacteriaceae & $\begin{array}{l}\text { Ethanol 2,3-butanediol } \\
\text { succinic acid }\end{array}$ & Batch & $24.82 \mathrm{~g} / \mathrm{L}$ & [62] \\
\hline Glycerol & Klebsiella pneumonia (XJ-Li) & Enterobacteriaceae & Ethanol lactate & Batch & $12.2 \mathrm{~g} / \mathrm{L}$ & [62] \\
\hline Glycerol & Klebsiella pneumonia (XJ-Li) & Enterobacteriaceae & Ethanol lactate & Fed-batch & $38.1 \mathrm{~g} / \mathrm{L}$ & [31] \\
\hline Glycerol & Lactobacillus reuteri ATCC 23272 & Lactobacillacae & - & - & $16.81 \mathrm{~g} / \mathrm{L}$ & {$[52]$} \\
\hline Glycerol & Clostridium (Strain AT1) & $\begin{array}{l}\text { Clostridiaceae } \\
\text { (Thermophilic } \\
\text { microorganisms) }\end{array}$ & - & Batch & $6.4 \mathrm{~g} / \mathrm{L}$ & {$[66]$} \\
\hline Glycerol & Caloramator viterbensis & $\begin{array}{l}\text { Clostridiaceae } \\
\text { (Thermophilic } \\
\text { microorganisms) }\end{array}$ & Acetic acid & Batch & $0.69 \mathrm{~mol} / \mathrm{mol}$ & [67] \\
\hline Crude Glycerol & Clostridium Pasteurianum & Clostridiaceae & Butanol & Batch & $169 \mathrm{mmol}$ & [59] \\
\hline Technical Glycerol & Clostridium Pasteurianum & Clostridiaceae & Butanol & Batch & $211 \mathrm{mmol}$ & [59] \\
\hline Glycerol & Clostridium Bifermentas & Clostridiaceae & $\begin{array}{l}\text { Ethanol lactic acid formic } \\
\text { acid acetic acid }\end{array}$ & Fed-batch & $16.98 \mathrm{~g} / \mathrm{L}$ & [60] \\
\hline
\end{tabular}

(Shell routes). It is synthesized through hydration of acrolein to 3-hydroxypropionaldehyde (3-HPA) and followed by catalytic hydrogenation of 3-HPA to form PDO. During the process, acrolein has a large tendency to polymerize through self-condensation. The hydration reaction has to compete with acrolein self-condensation to produce 3-HPA, thus the yield obtained in this process is low. The low conversion efficiency of the acrolein process, as well as the hazardous nature of acrolein, has spurred a great deal of interest in producing PDO from other chemical sources, especially glycerol $[20,72]$. Several well-known chemical conversion processes of PDO from glycerol are catalytic hydrogenolysis and dehydroxylation of glycerol.

Glycerol hydrogenolysis is a catalytic chemical process that breaks a chemical bond of carbon-carbon or carbon-oxygen in glycerol following by simultaneous addition of a hydrogen atom to form a molecular fragment [20]. In the catalytic hydrogenolysis process, bioglycerol can be converted into valuable products such as 1,2-propanediol (1,2-PDO), 1,3-propanediol (PDO) or ethylene glycol (EG). The catalytic hydrogenolysis pathways involve twostep reaction (Scheme 2.2): (Step 1) glycerol is dehydrated to 3-hydroxypropanal over acid sites, and (step 2) 3-hydroxypropanal is hydrogenolyzed to $1,3-\mathrm{PDO}$ over metal catalyst $[73,74]$. The selectivity toward 1,3-propanediol or 1,2-propanediol is highly dependent on the catalyst used and reaction conditions. Numerous studies were done to optimize the selectivity of 1,3-PDO.

2.2.1. Heterogeneous and homogeneous catalyst

Several studies on homogeneous and heterogeneous catalytic hydrogenolysis of glycerol to 1,3-PDO have been reported in recent years. Celanese Corporation filed a patent on homogeneous catalytic hydrogenolysis process of glycerol. The inventor developed the reaction over homogeneous rhodium complex catalyst under $32 \mathrm{MPa}$ syngas at $473 \mathrm{~K}$ in the presence of 1-methylpyrrolidinone and $\mathrm{H}_{2} \mathrm{WO}_{4}$ as promoter. The yield of 1,3-PDO obtained was $21.0 \%$ [75]. Shell also established a homogeneous catalytic system over Pd complex accompanied by sulfolane or water as solvent. The reaction was carried out under $6.0 \mathrm{MPa}$ syngas at $413 \mathrm{~K}$ and the selectivity of 1,3-PDO was $30.8 \%$ [76]. Schlaf et al. described the deoxygenation of glycerol via homogeneous catalytic system over ruthenium complex $\left[\left\{\mathrm{Cp}^{*} \mathrm{Ru}\right.\right.$ $\left.\left.(\mathrm{CO})_{2}\right\}_{2} \mathrm{Cu}-\mathrm{H}\right]^{+} \mathrm{OTf}^{-} \quad\left(\mathrm{Cp}^{*}=\eta^{5}-\mathrm{C}_{5} \mathrm{Me}_{5} ; \quad \mathrm{OTf}=\mathrm{OSO}_{2} \mathrm{CF}_{3}\right)$ at $383 \mathrm{~K}$ under $\mathrm{H}_{2}$ pressure 5.2 $\mathrm{MPa}$ in sulfolane solvent [77].

In order to overcome the separation problem of catalyst in homogeneous processes, many studies had been developed to hydrogenolyse glycerol over heterogeneous catalysts. Chaminand et al. hydrogenolyzed glycerol at $453 \mathrm{~K}$ under 80 bar $\mathrm{H}_{2}$-pressure in the presence of catalyst $(\mathrm{Cu}, \mathrm{Pd}, \mathrm{Rh})$ supported on zinc oxide, carbon or aluminium oxide in solvent such as water, dioxane and sulfolane. The authors demonstrated that the addition of tungstic acid $\left(\mathrm{H}_{2} \mathrm{WO}_{4}\right)$ which acts as an additive improved the selectivity toward 1,3-propanediol. The yield of PDO obtained was twice of that 1,2-PDO in the presence of $\mathrm{Rh} / \mathrm{C}$ catalyst with $\mathrm{H}_{2} \mathrm{WO}_{4}$ in sulfolane. Chaminand et al. suggested a general reaction mechanism to describe the effect of unlike parameters on the selectivity and activity on the product obtained (Scheme 2.3). They explained that with the presence of $\mathrm{H}_{2} \mathrm{WO}_{4}$, the reaction pathway could favor the dehydration process to form 3-hydroxypropanal or acetol as shown in route $A$. The additional of iron or copper in the 

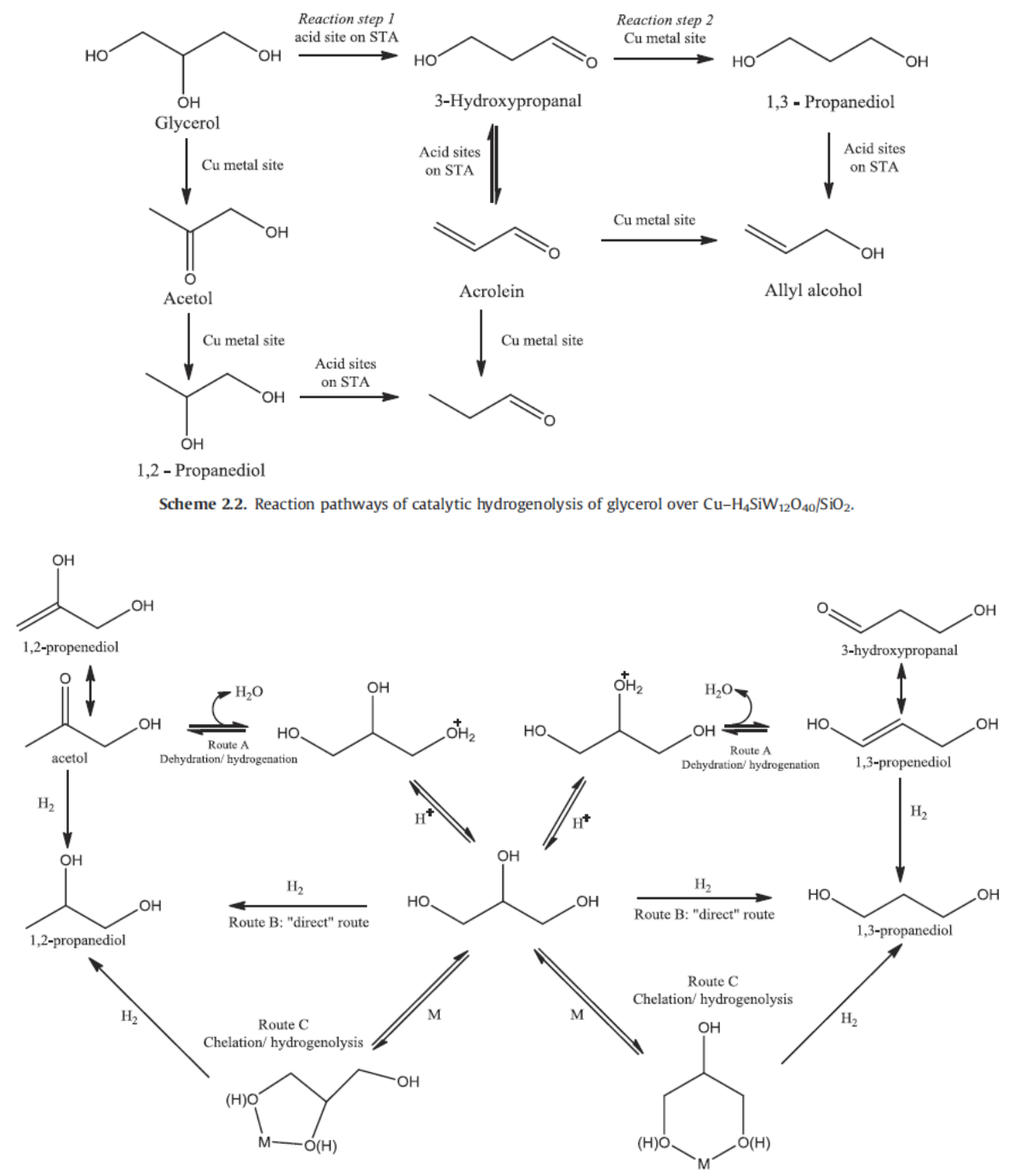

Scheme 2.3. The possible reaction mechanism for catalytic hydrogenolysis of glycerol.

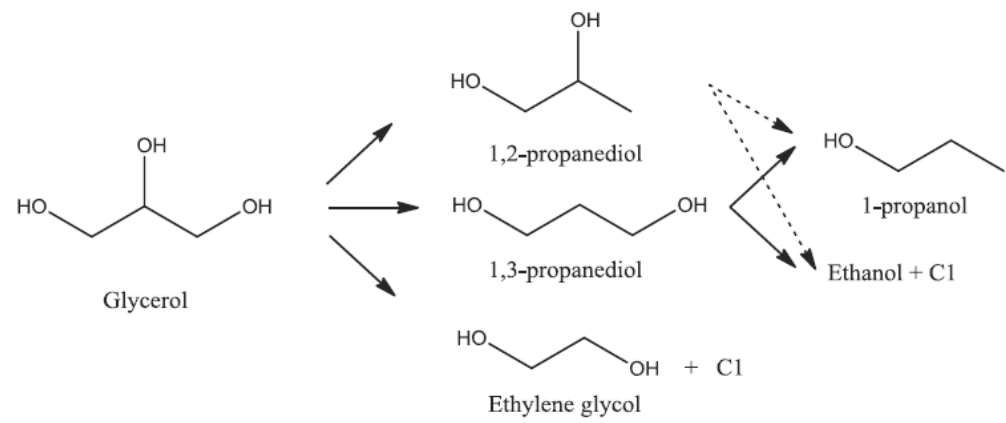

Scheme 2.4. Reaction scheme of hydrogenolysis of glycerol into various products.

Link to Full-Text Articles :

http://www.sciencedirect.com/science/article/pii/S1364032114008582 